Article

\title{
Evaluation of the Antibacterial Activity and Efflux Pump Reversal of Thymol and Carvacrol against Staphylococcus aureus and Their Toxicity in Drosophila melanogaster
}

\author{
Zildene de Sousa Silveira ${ }^{1,2} \mathbb{D}$, Nair Silva Macêdo ${ }^{1,2} \mathbb{D}^{\mathbb{D}}$, Joycy Francely Sampaio dos Santos ${ }^{1}$ (D), \\ Thiago Sampaio de Freitas ${ }^{3}$ (D) , Cristina Rodrigues dos Santos Barbosa ${ }^{3}$ (D), \\ Dárcio Luiz de Sousa Júnior ${ }^{1}\left(\mathbb{D}\right.$, Débora Feitosa Muniz ${ }^{3} \mathbb{D}$, Lígia Claudia Castro de Oliveira ${ }^{1}(\mathbb{D}$, \\ José Pinto Siqueira Júnior ${ }^{4}{ }^{(D)}$, Francisco Assis Bezerra da Cunha ${ }^{1}$ (D), \\ Henrique Douglas Melo Coutinho ${ }^{3, *(D)}$, Valdir Queiroz Balbino ${ }^{2}$ and Natália Martins $5,6, *$ (D) \\ 1 Laboratory of Semi-Arid Bioprospecting (LABSEMA), Regional University of Cariri-URCA, \\ Crato 63105-000, CE, Brazil; Zildenesousa15@gmail.com (Z.d.S.S.); naiirmacedo@gmail.com (N.S.M.); \\ joycy.sampaio22@gmail.com (J.F.S.d.S.); darciolsjr@gmail.com (D.L.d.S.J.); \\ ligiaclaudia@yahoo.com.br (L.C.C.d.O.); cunha.urca@gmail.com (F.A.B.d.C.) \\ 2 Graduate Program in Biological Sciences-PPGCB, Federal University of Pernambuco-UFPE, \\ Recife 50670-901, PE, Brazil; vqbalbino@gmail.com \\ 3 Laboratory of Microbiology and Molecular Biology (LMBM), Regional University of Cariri-URCA, \\ Crato 63105-000, CE, Brazil; thiagocrato@hotmail.com (T.S.d.F.); cristinase75@gmail.com (C.R.d.S.B.); \\ deehmuniz78@gmail.com (D.F.M.) \\ 4 Laboratory of Microorganism Genetics (LGM), Federal University of Paraiba-UFPB, \\ João Pessoa 58051-900, PB, Brazil; siqueira@dbm.ufpb.br \\ 5 Faculty of Medicine, University of Porto, Alameda Prof. Hernâni Monteiro, 4200-319 Porto, Portugal \\ 6 Institute for Research and Innovation in Health (i3S), University of Porto, 4200-135 Porto, Portugal \\ * Correspondence: hdmcoutinho@gmail.com (H.D.M.C.); ncmartins@med.up.pt (N.M.)
}

Academic Editors: Severina Pacifico and Simona Piccolella

Received: 9 April 2020; Accepted: 27 April 2020; Published: 30 April 2020

\begin{abstract}
The antibacterial activity and efflux pump reversal of thymol and carvacrol were investigated against the Staphylococcus aureus IS-58 strain in this study, as well as their toxicity against Drosophila melanogaster. The minimum inhibitory concentration (MIC) was determined using the broth microdilution method, while efflux pump inhibition was assessed by reduction of the antibiotic and ethidium bromide (EtBr) MICs. D. melanogaster toxicity was tested using the fumigation method. Both thymol and carvacrol presented antibacterial activities with MICs of 72 and $256 \mu \mathrm{g} / \mathrm{mL}$, respectively. The association between thymol and tetracycline demonstrated synergism, while the association between carvacrol and tetracycline presented antagonism. The compound and EtBr combinations did not differ from controls. Thymol and carvacrol toxicity against $D$. melanogaster were evidenced with $\mathrm{EC}_{50}$ values of 17.96 and $16.97 \mu \mathrm{g} / \mathrm{mL}$, respectively, with $48 \mathrm{~h}$ of exposure. In conclusion, the compounds presented promising antibacterial activity against the tested strain, although no efficacy was observed in terms of efflux pump inhibition.
\end{abstract}

Keywords: bacterial resistance; efflux pumps; terpenoids; thymol; carvacrol

\section{Introduction}

The prevalence of bacterial resistance to antibiotics, this being associated with increased mortality rates, has become a source of great concern for public health [1]. Staphylococcus aureus is a commensal 
microorganism associated with a wide variety of infections, since it has the capacity to acquire resistance to many classes of antibacterial agents, such as $\beta$-lactams, quinolones and macrolides $[2,3]$.

There are several mechanisms by which $S$. aureus develops resistance to antimicrobials, including limited drug absorption, target modification, enzymatic inactivation and active efflux mechanisms [4]. The latter, also known as efflux pumps, are proteins integrated into the bacterial plasma membrane that reduce the intracellular concentration of antibiotics by extruding them from the cell [5]. Among these pumps, the TetK pump, belonging to the major facilitator superfamily (MFS), is present in S. aureus IS-58 strain. TetK powers its transport activity with energy derived from proton gradients and is responsible for resistance to the tetracycline class of antibiotics [6].

Given the above, the development of efflux pump inhibitors that act as competitive and non-competitive adjuvants to reduce antibiotic resistance has attracted the attention of researchers [7]. Natural bacterial resistance modifiers can facilitate the reintroduction of ineffective therapeutic antibiotics in the clinic, reducing the toxic risks of these drugs by acting as efflux system regulators or as efflux pump inhibitors (EPIs) when blocking their activity [8,9].

The compounds thymol and carvacrol are two phenolic terpenoids, geometric isomers, which can be found in the form of translucent crystals and a yellowish liquid, respectively, at room temperature. Both are obtained from essential oils, mainly from thyme (Thymus vulgaris L.) and oregano (Origanum vulgare L.) [10], where a number of pharmacological properties associated with these compounds have been previously described in the literature, including antifungal [11] and antibacterial activities [12,13]. Although some compounds are capable of acting as EPIs, their high eukaryotic cell toxicity prevents their development as EPIs [14]. Thus, studies assessing the toxicity of these substances are necessary. Drosophila melanogaster is a model organism in toxicological assays which aim to understand the genetic and molecular mechanisms of toxic substances since these are very sensitive to different concentrations of toxic substances [15].

Thus, the objective of this study was to assess the antibacterial activity and efflux pump reversal mechanisms of the isomers thymol and carvacrol against the $S$. aureus IS-58 bacterial strain and to evaluate their toxicity in a D. melanogaster model.

\section{Results}

\subsection{Minimum Inhibitory Concentration (MIC)}

The monoterpenes thymol and carvacrol demonstrated relevant direct antibacterial activity against the $S$. aureus IS-58 strain, with MIC values of $72 \mu \mathrm{g} / \mathrm{mL}$ and $256 \mu \mathrm{g} / \mathrm{mL}$, respectively (Table 1), where the MIC value for thymol was more effective than that of the standard antibiotic tetracycline, with values varying between 128 and $114 \mu \mathrm{g} / \mathrm{mL}$.

Table 1. Minimum inhibitory concentrations (MIC, $\mu \mathrm{g} / \mathrm{mL}$ ) of thymol, carvacrol and tetracycline against the $S$. aureus IS-58 strain.

\begin{tabular}{cccc}
\hline Strain & \multicolumn{3}{c}{ MIC $(\mu \mathrm{g} / \mathrm{mL})$} \\
\hline \multirow{2}{*}{ S. aureus IS-58 } & Thymol & Carvacrol & Tetracycline \\
& 72 & 256 & 128 \\
\hline
\end{tabular}

\subsection{Modulatory Effect over Antibiotic Activity and Ethidium Bromide}

When thymol was combined at a sub-inhibitory concentration (MIC/8) with tetracycline, an interference of the antibiotic activity was observed, where a MIC reduction from 114 to $101 \mu \mathrm{g} / \mathrm{mL}$ was seen (Figure 1A). When the antibiotic was tested in association with standard inhibitors, the MIC values for chlorpromazine did not differ from the control, whereas in association with CCCP, a reduction in the antibiotic MIC was observed, indicating greater specificity of this inhibitor for the tested pump, with inhibition of the antibiotic resistance mechanism being observed.

With respect to efflux pump inhibition, the assays with ethidium bromide (EtBr) as a pump substrate found the association between thymol and $\mathrm{EtBr}$ did not differ from the control. Thus, the observed 
action of the compound, when in association with the antibiotic, suggests an activity over a resistance mechanism other than active efflux (Figure 1B).

IS-58

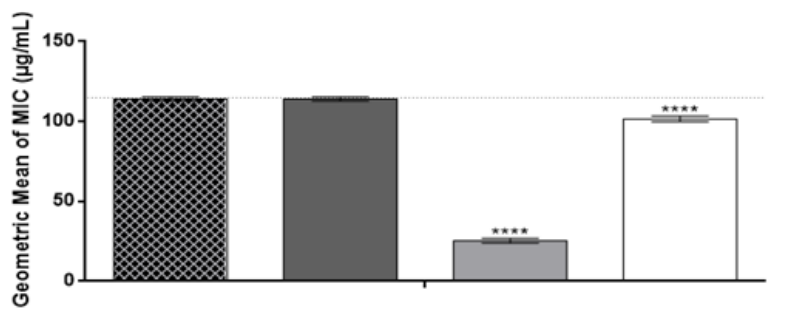

IS-58

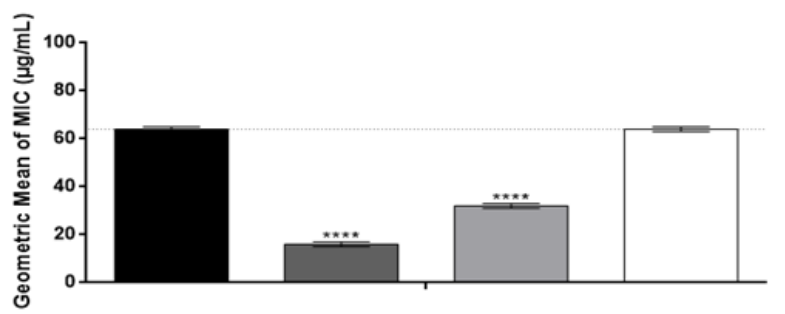

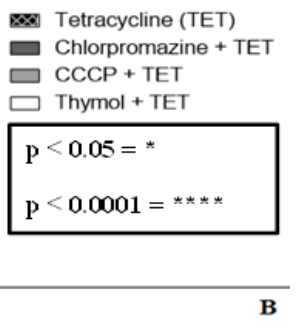

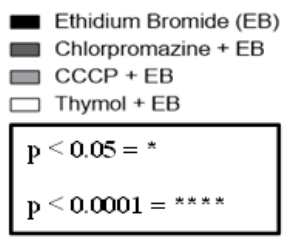

Figure 1. Effect of the association between thymol and tetracycline (A) and thymol and ethidium bromide (B) over S. aureus IS-58, expressing the TetK efflux protein. CCCP = carbonyl cyanide m-chlorophenylhydrazone; ${ }^{*} p<0.05 ; * * * p<0.0001$.

The data regarding the combined effect of carvacrol and tetracycline reported an antagonism, with the MIC value increasing from 128 to $203 \mu \mathrm{g} / \mathrm{mL}$ (Figure 2A). However, the results for the association of carvacrol with chlorpromazine did not differ from the control, while a synergism resulting from its association with carvacrol was observed for CCCP.

IS-58
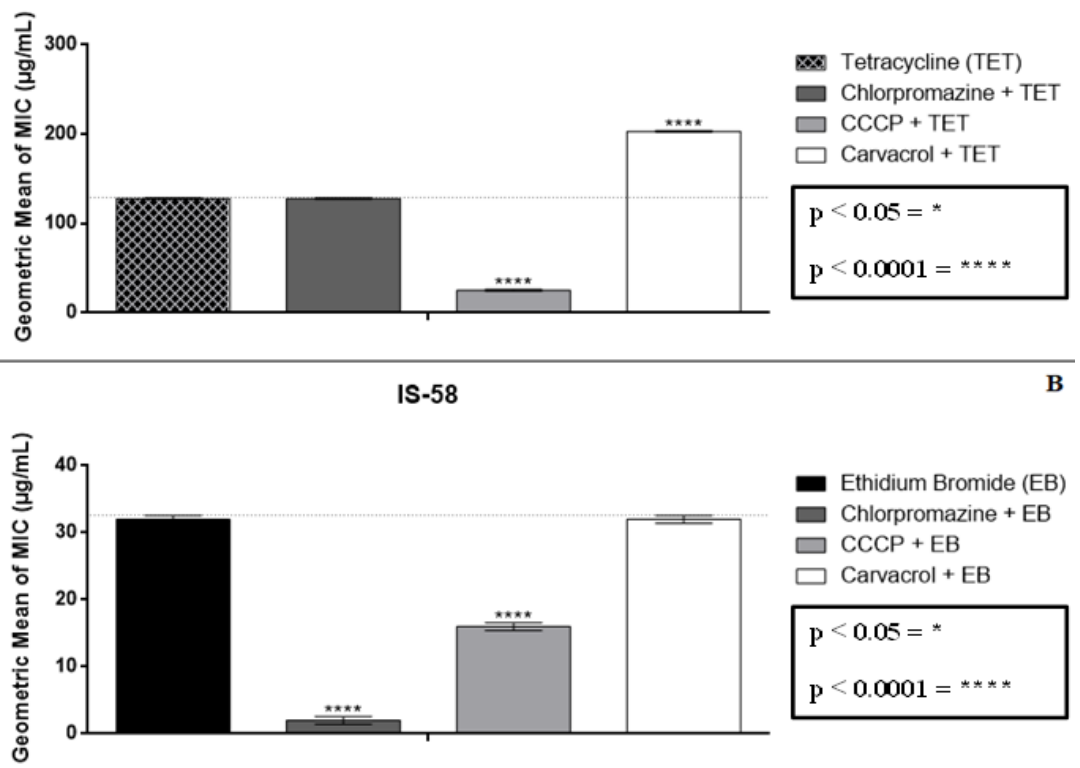

$$
\begin{aligned}
& \square \text { Ethidium Bromide (EB) } \\
& \text { Chlorpromazine + EB } \\
& \text { CCCP + EB } \\
& \square \text { Carvacrol + EB } \\
& \hline \mathrm{p}<\mathbf{0 . 0 5}=* \\
& \mathrm{p}<\mathbf{0 . 0 0 0 1}=* * *
\end{aligned}
$$

Figure 2. Effect of the association between carvacrol and tetracycline (A) and carvacrol and ethidium bromide (B) over S. aureus IS-58, expressing the TetK efflux protein. CCCP = carbonyl cyanide m-chlorophenylhydrazone; ${ }^{*} p<0.05 ;{ }^{* * *} p<0.0001$. 
When the EPI effect was evaluated using the MIC reduction of EtBr by carvacrol, the association was shown to not differ from the control, while standard inhibitors synergistically modulated this, demonstrating the presence of an efflux pump mechanism (Figure 2B).

The results observed in the graphs above indicate the presence of an efflux mechanism that is sensitive to the CCCP inhibitor when tested in association with the antibiotic against the S. aureus IS-58 strain. Furthermore, the association with EtBr demonstrated presence of an efflux pump mechanism sensitive to both standard inhibitors, which shows that the antibacterial activity exhibited by both thymol and carvacrol against $S$. aureus is not due to an EPI effect.

\subsection{Drosophila Melanogaster Toxicity Assay and Negative Geotaxis}

The monoterpenes thymol and carvacrol presented marked toxicity against $D$. melanogaster with $\mathrm{EC}_{50}$ values of $17.96 \mu \mathrm{g} / \mathrm{mL}$ and $16.97 \mu \mathrm{g} / \mathrm{mL}$, respectively, within $48 \mathrm{~h}$ of exposure to the products. The mortality tests using thymol found the highest concentration tested, $31 \mu \mathrm{g} / \mathrm{mL}$, and caused significant mortality compared to the control and the other concentrations from the first reading performed, which corresponded to $3 \mathrm{~h}$ of exposure to the compound (Figure 3A).

\section{Thymol Survival}

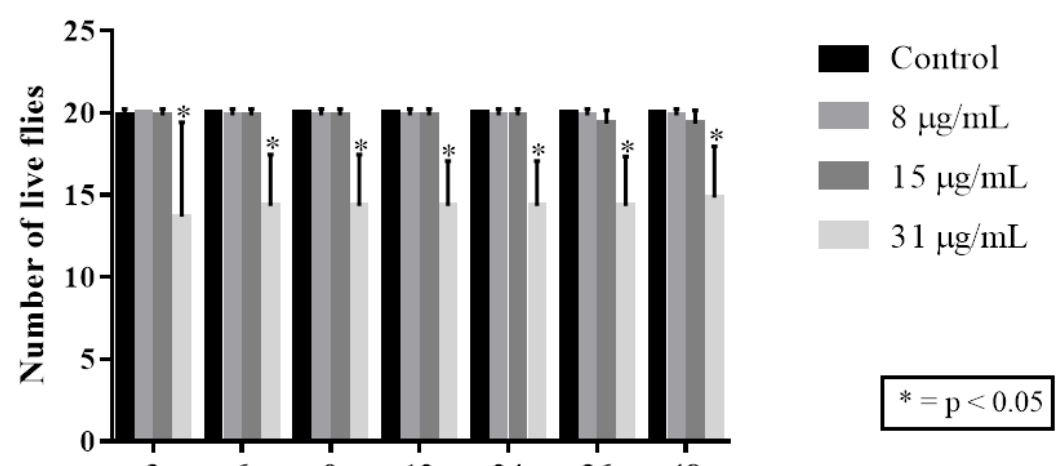

(A)

\section{Carvacrol Survival}

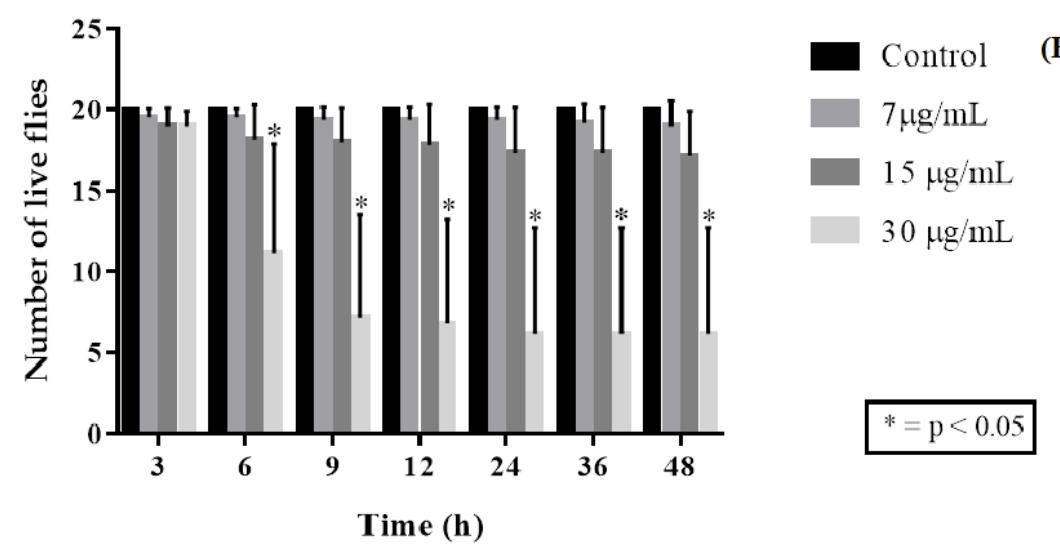

Figure 3. Toxic effect of different thymol (A) and carvacrol (B) concentrations on D. melanogaster.

In the 6 to 48 -h readings, the concentration-dependent toxicity pattern remained constant, where the 8 and $15 \mu \mathrm{g} / \mathrm{mL}$ concentrations did not show significant differences compared to the control with respect to the number of dead flies. For carvacrol, a toxicity for this compound was found at $30 \mu \mathrm{g} / \mathrm{mL}$, this being the most potent, since it began to differ statistically from the control after the first $6 \mathrm{~h}$ of exposure, becoming more effective throughout the exposure readings, showing a high mortality rate in the flies. The 7 and $15 \mu \mathrm{g} / \mathrm{mL}$ concentrations were not significant compared to the 
control (Figure 3B). Damage to locomotor capacity following exposure to thymol was determined by the negative geotaxis test, in which the $31 \mu \mathrm{g} / \mathrm{mL}$ concentration was found to cause damage to the D. melanogaster locomotor apparatus following $3 \mathrm{~h}$ of exposure to the compound, this being statistically significant compared to the control and the other concentrations (Figure 4A). The mobility of the flies was scarcely affected by the 8 and $15 \mu \mathrm{g} / \mathrm{mL}$ concentrations, with no statistically significant interferences in fly locomotion compared to the control group.

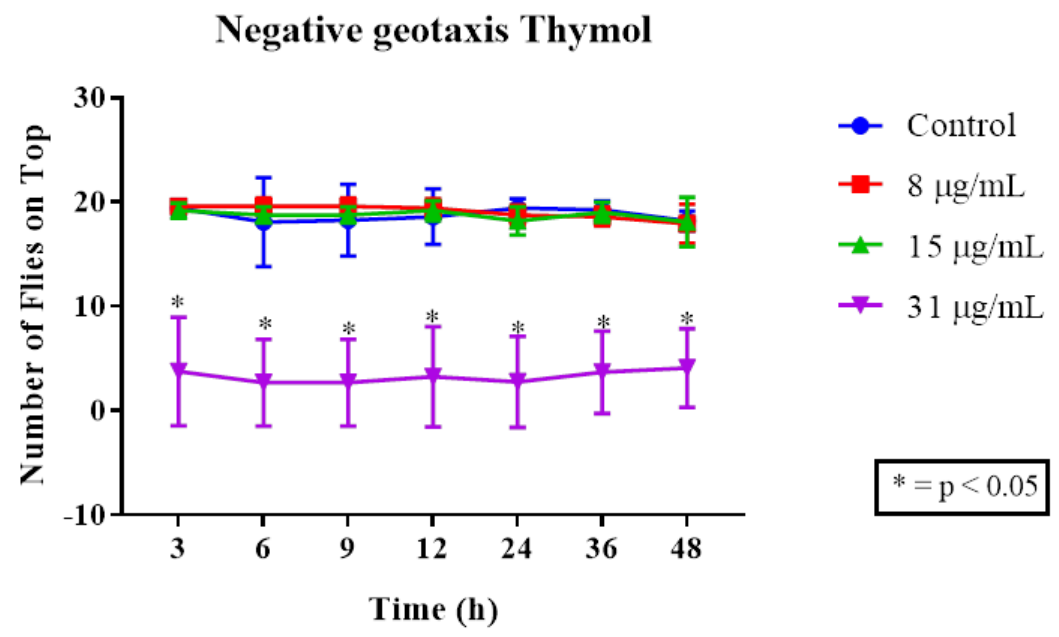

(A)

Negative geotaxis Carvacrol

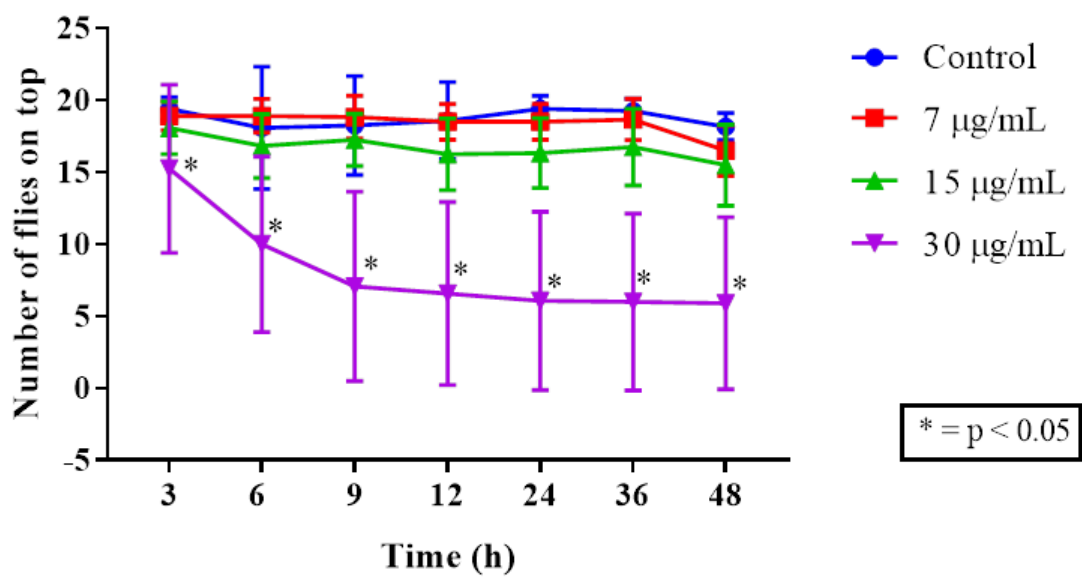

(B)

Figure 4. Toxic effect of varying thymol (A) and carvacrol (B) concentrations on the locomotor ability of D. melanogaster.

In the locomotor system damage assessment, a marked decline in the behavioral response of the flies was observed when these were exposed to a $30 \mu \mathrm{g} / \mathrm{mL}$ concentration, from the first $3 \mathrm{~h}$ of exposure to the compound. This effect was intensified in the following hours, such that by the 24-h reading the live flies showed great locomotor difficulties (Figure 4B).

\section{Discussion}

In this work, our results indicated that thymol and carvacrol exert relevant antibacterial activity, with MIC values of 72 and $256 \mu \mathrm{g} / \mathrm{mL}$ respectively, against the $S$. aureus IS-58 strain. These results are in accordance with that reported by Miladi et al. [16], in which thymol and carvacrol obtained MIC values of 64 and $256 \mu \mathrm{g} / \mathrm{mL}$, respectively, against the S. aureus ATCC 25923 strain. Lambert et al. [17] also reported a greater antibacterial activity for thymol compared to carvacrol against S. aureus ATCC 6538. 
These results may be justified by the hydrophobic nature and low solubility of thymol in the hydrophobic domain of the cytoplasmic membrane of bacterial cells. [18].

The structural differences in the hydroxyl group $(\mathrm{OH})$ position in both thymol and carvacrol isomers did not affect the inhibitory effect against the assayed bacterial strain. By the same reason, the relative position of the hydroxyl group in the phenolic ring also failed to strongly influence the degree of antibacterial activity for thymol and carvacrol against Bacillus cereus, S. aureus and Pseudomonas aeruginosa [19]. However, the study by Dorman and Deans [20] reported that carvacrol and thymol act differently against gram-positive and gram-negative species. Our results evidenced an interference in the antibiotic activity when thymol and tetracycline were associated, resulting in a reduction of the MIC value of tetracycline from 114 to $101 \mu \mathrm{g} / \mathrm{mL}$. However, Davies and Wright [21] stated in their study that when a compound is in association with an inhibitor, only a minimum of a 3-fold MIC reduction is acceptable as significant in terms of inhibiting resistance mechanisms, when carvacrol was associated with tetracycline an antagonism can be observed. These results are different from that observed by Cirino et al. [22], where thymol and carvacrol, used at sub-inhibitory concentrations (MIC/4), reduced the MIC value of tetracycline from $64 \mu \mathrm{g} / \mathrm{mL}$ to $32 \mu \mathrm{g} / \mathrm{mL}$ in both cases.

The TetK efflux pump is the main mechanism for bacterial resistance to tetracycline, being coded by the plasmid gene pt 181 . The main efflux protein protects the bacterial ribosome by extruding the antibiotic out of the bacterial cell [23]. Many studies have been conducted to face the bacterial resistance to antibiotics, mainly through using compounds that act as adjuvants to the antibiotic activity. For this reason, it is known that natural products and phytochemicals act synergistically with this objective [24-26]. In our assays, thymol and carvacrol had no effect as EPIs. Due to the fact that efflux pumps are the unique mechanism for EtBr extrusion, the MIC reduction of the EtBr indicates an EPI effect [27]. Thus, our results indicate that thymol and carvacrol act on other resistance mechanisms, regardless of the active efflux.

Given these results, we also investigated the thymol and carvacrol toxicity against $D$. melanogaster. Similar findings were also stated by Zhang et al. [28], who demonstrated that oxygenated monoterpenes, such as thymol and carvacrol, exhibited high toxicity against $D$. melanogaster while investigating the fumigant toxicity of monoterpenes against fruit flies. Negative geotaxis consists of flies' ability to move vertically, this being a common locomotion behavior associated with $D$. melanogaster [29]. The results found in this study corroborate data from the investigation by Karpouhtsis et al. [30], which reported an insecticidal and genotoxic activity for thymol against $D$. melanogaster. Previous studies also report a repellent activity for thymol against Culex pipiens pallens [31], as well as a toxic effect for its larvae [32].

The insecticidal potential of terpenoids has been associated with their low molecular weights, which makes them highly volatile, with these being often considered toxic or repellent against insects, where different functional groups and their locations seem to influence their biological effectiveness [33]. The toxicity mechanisms and locomotor capacity impairments produced by many compounds and/or essential oil may be associated with a decrease in AChE activity, which, considering its importance against neurotoxicity, functions as defense in stressful situations [34,35]. Another factor also reported in the literature is the increase in the biosynthesis of heat shock proteins, such as $h s p 70$, which support the functional structure of important enzymes and proteins, as an insect's self-defense mechanism against stressors [36].

\section{Materials and Methods}

\subsection{Bacterial Strain and Culture Media}

The IS-58 S. aureus strain (gently furnished by Dr. Simon Gibbons, from the Imperial College, London, UK), with the PT181 plasmid carrying the gene for the tetracycline efflux protein TetK, was used. The culture media used in the tests were heart infusion agar (HIA, laboratories Difco Ltd.a., Campinas, Brazil) prepared according to the manufacturer and 10\% brain heart infusion (BHI, laboratories Difco Ltd.a.) broth. 


\subsection{Substances}

The antibiotic tetracycline, as well as thymol and carvacrol, were diluted in dimethyl sulfoxide (DMSO) and in sterile water to a final concentration of $1024 \mu \mathrm{g} / \mathrm{mL}$. The DMSO proportion used was lower than 5\%. Chlorpromazine and $\mathrm{EtBr}$ were dissolved in sterile distilled water, while carbonyl cyanide m-chlorophenylhydrazone (CCCP) was dissolved in methanol/water (1:3, v/v). All substances were diluted until reaching a concentration of $1024 \mu \mathrm{g} / \mathrm{mL}$. The molecular structures of the compounds were obtained using the software ACD/ChemSketch (ACD/LABS, Toronto, ON, Canada) (Figure 5).

\subsection{Determining the Minimum Inhibitory Concentration (MIC)}

The MIC was determined for the isolated compounds thymol and carvacrol as per the broth microdilution method proposed by Javadpour et al. [37], with some adaptations. The inoculants were prepared $24 \mathrm{~h}$ after sowing the strains. Eppendorfs ${ }^{\circledR}$ were filled with $1440 \mu \mathrm{L}$ of $\mathrm{BHI}$ and $160 \mu \mathrm{L}$ of the inoculum. The plates were then filled with $100 \mu \mathrm{L}$ of the final solution. Microdilution was performed with $100 \mu \mathrm{L}$ of the products. Following $24 \mathrm{~h}$ of incubation, readings were taken by the addition of resazurin (7-hydroxy-3H-phenoxazine-3-one 10-oxide) [38]. The tests were performed in triplicates.

\subsection{Evaluation of Efflux Pump Inhibition}

Efflux pump inhibition was carried out using the methodology adapted from Coutinho et al. [39]. Eppendorfs ${ }^{\circledR}$ were filled with $160 \mu \mathrm{L}$ of the inoculum, the sub-inhibitory concentration (MIC/8) of the compounds, and completed with BHI until reaching a volume of $1.6 \mathrm{~mL}$. Microdilution was performed with $100 \mu \mathrm{L}$ of the antibiotics, and readings were taken $24 \mathrm{~h}$ after incubation by adding resazurin [38]. The modulatory effect of the combination of the antibiotic, as well as EtBr, with the compounds' thymol and carvacrol was tested using a methodology adapted from Coutinho et al. [39] (Figure 5). For this, Eppendorfs ${ }^{\circledR}$ were filled with $160 \mu \mathrm{L}$ of the inoculum with the compounds at sub-inhibitory concentrations (MIC/8) and completed with BHI until reaching a volume of $1.6 \mathrm{~mL}$. A modulatory control was prepared with $160 \mu \mathrm{L}$ of the inoculum and $1440 \mu \mathrm{L}$ of BHI. Thereafter, the microdilution plates were filled, with rows $\mathrm{G}$ and $\mathrm{H}$ corresponding to the microbial growth controls. Sterility controls were performed on separate plates. Subsequently, microdilutions were performed with the antibiotic and EtBr $(100 \mu \mathrm{L})$. After $24 \mathrm{~h}$, readings were taken in the same manner as for the MIC tests. The tests were performed in triplicates.

Thymol

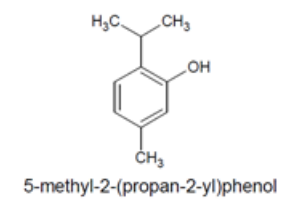

Tetracycline

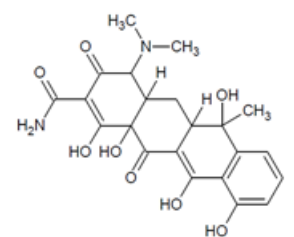

(4S,4aS, 5aS,6S, 12aR)-4-(dimethylamino)-1,6,10,11,12a-pentahydroxy-6methyl-3,12-dioxo-4,4a,5,5a-tetrahydrotetracene-2-carboxamide

(A)

(C)
Carvacrol

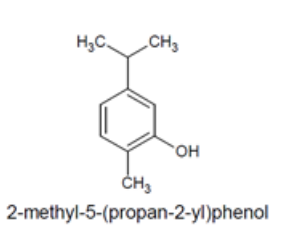

Ethidium Bromide (EtBr)

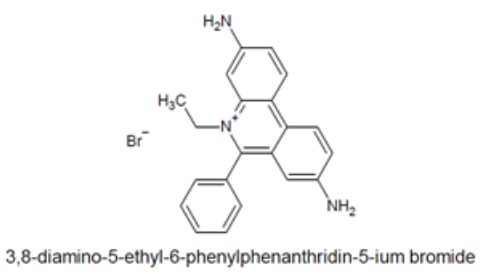

Figure 5. Chemical structures of thymol (A), carvacrol (B), tetracycline (C) and ethidium bromide (D). 


\subsection{Drosophila melanogaster Toxicity Assays}

The fumigation bioassay method proposed by Cunha et al. [40] was used to assess toxicity. Adult flies (males and females), in multiples of 20, were placed in $130 \mathrm{~mL}$ flasks, previously prepared with $1 \mathrm{~mL}$ of $20 \%$ sucrose solution. The compound doses were impregnated in the glass cover on filter paper. The control received $20 \mu \mathrm{L}$ of acetone, while the compounds were prepared at the concentrations of $200 \mu \mathrm{g} / \mathrm{mL}$ for thymol and $195.2 \mu \mathrm{g} / \mathrm{mL}$ for carvacrol, both diluted in acetone. Volumes of 20, 10 and $5 \mu \mathrm{L}$ were taken from the stock solutions, resulting in the final concentrations of 31,15 and $8 \mu \mathrm{g} / \mathrm{mL}$ in bottles with $130 \mathrm{~mL}$ of air for thymol and 30, 15 and $7 \mu \mathrm{g} / \mathrm{mL}$ in bottles with $130 \mathrm{~mL}$ of air for carvacrol, respectively.

The bioassays were conducted in a BOD-type greenhouse under controlled conditions. The tests were performed in triplicates and mortality rate readings were performed at 3, 6, 12, 24, 36 and $48 \mathrm{~h}$ [40].

\subsection{Negative Geotaxis Assays}

Damage to the locomotor system was determined as described by Coulom and Birman [41], after considering fly mortality. The negative geotaxis assay consists of counting the number of flies that rise above $3 \mathrm{~cm}$ in the experimental glass column during a $5 \mathrm{~s}$ time interval. The assays were repeated twice within a $1 \mathrm{~min}$ interval. The results were presented as the mean time $(\mathrm{s}) \pm \mathrm{SE}$ obtained from three independent experiments.

\subsection{Statistical Analysis}

A two-way analysis of variance (ANOVA) followed by Bonferroni's post hoc test was employed for the microbiological assays using GraphPad Prism 7.0 software (GraphPad Software, San Diego, CA, USA). Meanwhile, a two-way ANOVA followed by Tukey's multiple comparisons test was performed for the toxicity data analysis.

\section{Conclusions}

The monoterpenes thymol and carvacrol presented direct antibacterial activity against the $S$. aureus IS-58 strain, where the strain was shown to be more sensitive to thymol, with the isomeric difference being a possible factor in terms of antibacterial activity. However, despite the demonstrated antibiotic activity results, the compounds were ineffective at inhibiting the TetK efflux pump mechanism, thus indicating that the antibacterial activity of the compounds is not associated with this resistance mechanism. Thymol and carvacrol exerted a marked toxic activity against $D$. melanogaster.

Author Contributions: Conceptualization, F.A.B.d.C., N.M., H.D.M.C.; methodology, Z.d.S.S., J.F.S.d.S., T.S.d.F., C.R.d.S.B.; validation, N.S.M.; formal analysis, D.L.d.S.J., D.F.M.; resources, J.P.S.J., L.C.C.d.O.; writing-original draft preparation, Z.d.S.S, V.Q.B.; writing—review and editing, F.A.B.d.C., N.M., H.D.M.C.; supervision, F.A.B.d.C., N.M., H.D.M.C. All authors have read and agreed to the published version of the manuscript.

Funding: This study was funded by the Fundação Cearense de Apoio ao Desenvolvimento Científico e TecnológicoFUNCAP (BP3-0139-00077.01.00/18).

Conflicts of Interest: The authors declare no conflicts of interest.

\section{References}

1. Porse, A.; Schou, T.S.; Munck, C.; Ellabaan, M.M.H.; Sommer, A.O. Biochemical mechanisms determine the functional compatibility of heterologous genes. Nat. Commun. 2018, 9, 522. [CrossRef] [PubMed]

2. Foster, T.J. Antibiotic resistance in Staphylococcus aureus. Current status and future prospects. FEMS Microbiol. Rev. 2017, 41, 430-449. [CrossRef] [PubMed]

3. Sun, J.; Deng, Z.; Yan, A. Bacterial multidrug efflux pumps: Mechanisms, physiology and pharmacological exploitations. Biochem. Biophys. Res. Commun. 2014, 453, 254-267. [CrossRef] [PubMed]

4. Yilmaz, E.Ş.; Aslantaş, Ö. Antimicrobial resistance and underlying mechanisms in Staphylococcus aureus isolates. Asian Pac. J. Trop. Med. 2017, 10, 1059-1064. [CrossRef] 
5. Jang, S. Multidrug efflux pumps in Staphylococcus aureus and their clinical implications. J. Microbiol. 2016, 54, 1-8. [CrossRef]

6. Bhardwaj, A.K.; Mohanty, P. Bacterial efflux pumps involved in multidrug resistance and their inhibitors: Rejuvinating the antimicrobial chemotherapy. Recent Pat. Anti-Infect. Drug Discov. 2012, 7, 73-89. [CrossRef]

7. Mahmood, H.Y.; Jamshidi, S.; Sutton, M.J.; Rahman, K.M. Current advances in developing inhibitors of bacterial multidrug efflux pumps. Curr. Med. Chem. 2016, 23, 1062-1081. [CrossRef]

8. Abreu, A.C.; Mcbain, A.J.; Simoes, M. Plants as sources of new antimicrobials and resistance-modifying agents. Nat. Prod. Rep. 2012, 29, 1007-1021. [CrossRef]

9. Pagès, J.M.; Amaral, L. Mechanisms of drug efflux and strategies to combat them: Challenging the efflux pump of Gram-negative bacteria. Biochim. Biophys. Acta (Baa)-Protein Struct. Mol. Enzym. 2009, 1794, 826-833.

10. Kowalcze, M.; Jakubowska, M. Multivariate approach in voltammetric identification and simultaneous determination of eugenol, carvacrol, and thymol on boron-doped diamond electrode. Mon. Chem. Chem. Mon. 2019, 150, 991-1002. [CrossRef]

11. Braga, P.C.; Alfieri, M.; Culici, M.; Dal Sasso, M. Inhibitory activity of thymol against the formation and viability of Candida albicans hyphae. Mycoses 2007, 50, 502-506. [CrossRef] [PubMed]

12. Fadil, M.; Fikri-Benbrahim, K.; Rachiq, S.; Ihssane, B.; Lebrazi, S.; Chraibi, M.; Farah, A. Combined treatment of Thymus vulgaris L., Rosmarinus officinalis L. and Myrtus communis L. essential oils against Salmonella typhimurium: Optimization of antibacterial activity by mixture design methodology. Eur. J. Pharm. Biopharm. 2018, 126, 211-220. [CrossRef] [PubMed]

13. Vincenzi, M.; Stammati, A.; Vincenzi, A.; Silano, M. Constituents of aromatic plants: Carvacrol. Fitoterapia 2004, 75, 801-804. [CrossRef] [PubMed]

14. Limaverde, P.W.; Campina, F.F.; Cunha, F.A.; CRISPIM, F.D.; Figueredo, F.G.; Lima, L.F.; Tintino, S.R. Inhibition of the TetK efflux-pump by the essential oil of Chenopodium ambrosioides L. and $\alpha$-terpinene against Staphylococcus aureus IS-58. Food Chem. Toxicol. 2017, 109, 957-961. [CrossRef]

15. Rand, M.D.; Montgomery, S.L.; Prince, L.; Vorojeikina, D. Developmental toxicity assays using the Drosophila model. Curr. Protoc. Toxicol. 2014, 59, 1-12. [CrossRef]

16. Miladi, H.; Zmantar, T.; Chaabouni, Y.; Fedhila, K.; Bakhrouf, A.; Mahdouani, K.; Chaieb, K. Antibacterial and efflux pump inhibitors of thymol and carvacrol against food-borne pathogens. Microb. Pathog. 2016, 99, 95-100. [CrossRef]

17. Lambert, R.J.W.; Skandamis, P.N.; Coote, P.J.; Nychas, G.J. A study of the minimum inhibitory concentration and mode of action of oregano essential oil, thymol and carvacrol. J. Appl. Microbiol. 2001, 1, 453-462. [CrossRef]

18. Trombetta, D.; Castelli, F.; Sarpietro, M.G.; Venuti, V.; Cristani, M.; Daniele, C.; Bisignano, G. Mechanisms of antibacterial action of three monoterpenes. Antimicrob. Agents Chemother. 2005, 49, 2474-2478. [CrossRef]

19. Obaidat, R.M.; Bader, A.; Al-Rajab, W.; Sheikha, G.A.; Obaidat, A.A. Preparation of mucoadhesive oral patches containing tetracycline hydrochloride and carvacrol for treatment of local mouth bacterial infections and candidiasis. Sci. Pharm. 2011, 79, 197-212. [CrossRef]

20. Dorman, H.J.D.; Deans, S.G. Antimicrobial agents from plants: Antibacterial activity of plant volatile oils. J. Appl. Microbiol. 2000, 88, 308-316. [CrossRef]

21. Davies, J.; Wright, G.D. Bacterial resistance to aminoglycoside antibiotics. Trends Microbiol. 1997, 5, $234-240$. [CrossRef]

22. Cirino, I.C.S.; Menezes-Silva, S.M.P.; Silva, H.T.D.; Souza, E.L.; Siqueira-Júnior, J.P. The essential oil from Origanum vulgare L. and its individual constituents carvacrol and thymol enhance the effect of tetracycline against Staphylococcus aureus. Chemotherapy 2014, 60, 290-293. [CrossRef] [PubMed]

23. Khan, S.A.; Novick, R.P. Complete nucleotide sequence of pT181, a tetracycline-resistance plasmid from Staphylococcus aureus. Plasmid 1983, 10, 251-259. [CrossRef]

24. Andrade, L.M.S.; Oliveira, A.B.M.; Leal, A.L.A.B.; Alcântara, F.A.O.; Portela, A.L.; Lima Neto, J.D.S.; Barreto, H.M. Antimicrobial activity and inhibition of the NorA efflux pump of Staphylococcus aureus by extract and isolated compounds from Arrabidaea brachypoda. Microb. Pathog. 2020, 40, 103935. [CrossRef]

25. Nafis, A.; Kasrati, A.; Jamali, C.A.; Custódio, L.; Vitalini, S.; Iriti, M.; Hassani, L. A Comparative Study of the in Vitro Antimicrobial and Synergistic Effect of Essential Oils from Laurus nobilis L. and Prunus armeniaca L. from Morocco with Antimicrobial Drugs: New Approach for Health Promoting Products. Antibiotics 2020, 9, 140. [CrossRef] [PubMed] 
26. Liu, Q.; Niu, H.; Zhang, W.; Mu, H.; Sun, C.; Duan, J. Synergy among thymol, eugenol, berberine, cinnamaldehyde and streptomycin against planktonic and biofilm-associated food-borne pathogens. Lett. Appl. Microbiol. 2015, 60, 421-430. [CrossRef]

27. Kaatz, G.W.; Moudgal, V.V.; Seo, S.M.; Kristiansen, J.E. Fenotiazinas e tioxantenos inibem a atividade da bomba de efluxo de múltiplas drogas no Staphylococcus aureus. Antimicrob. E Quim. 2003, 47, 719-726.

28. Zhang, Z.; Yang, T.; Zhang, Y.; Wang, L.; Xie, Y. Fumigant toxicity of monoterpenes against fruitfly, Drosophila melanogaster. Ind. Crop. Prod. 2016, 81, 147-151. [CrossRef]

29. Rhodenizer, D.; Martin, I.; Bhandari, P.; Pletcher, S.D.; Grotewiel, M. Genetic and environmental factors impact age-related impairment of negative geotaxis in Drosophila by altering age-dependent climbing speed. Exp. Gerontol. 2008, 43, 739-748. [CrossRef]

30. Karpouhtsis, I.; Pardali, E.; Feggou, E.; KokkinI, S.; Scouras, Z.G.; Mavragani-Tsipidou, P. Insecticidal and genotoxic activities of oregano essential oils. J. Agric. Food Chem. 1998, 46, 1111-1115. [CrossRef]

31. Zahran, H.E.D.M.; Abdelgaleil, A.S. Insecticidal and developmental inhibitory properties of monoterpenes on Culex pipiens L. (Diptera: Culicidae). J. Asia-Pac. Entomol. 2011, 14, 46-51. [CrossRef]

32. Park, B.S.; Choi, W.S.; Kim, J.H.; Kim, K.H.; Lee, S.E. Monoterpenes from thyme (Thymus vulgaris) as potential mosquito repellents. J. Am. Mosq. Control Assoc. 2005, 21, 80-84. [CrossRef]

33. Moreira, X.; Abdala-Roberts, L.; Nell, C.S.; Vázquez-González, C.; Pratt, J.D.; Keefover-Ring, K.; Mooney, K.A. Sexual and genotypic variation in terpene quantitative and qualitative profiles in the dioecious shrub Baccharis salicifolia. Sci. Rep. 2019, 9, 1-10. [CrossRef]

34. Calisi, A.; Lionetto, M.G.; Schettino, T. Biomarker response in the earthworm Lumbricus terrestris exposed to chemical pollutants. Sci. Total Environ. 2011, 409, 4456-4464. [CrossRef] [PubMed]

35. Hu, X.; Fu, W.; Yang, X.; Mu, Y.; Gu, W.; Zhang, M. Effects of cadmium on fecundity and defence ability of Drosophila melanogaster. Ecotoxicol. Environ. Saf. 2019, 171, 871-877. [CrossRef] [PubMed]

36. Basile, A.; Sorbo, S.; Lentini, M.; Conte, B.; Esposito, S. Water pollution causes ultrastructural and functional damages in Pellia neesiana (Gottsche) Limpr. J. Trace Elem. Med. Biol. 2017, 43, 80-86. [CrossRef] [PubMed]

37. Javadpour, M.M.; Juban, M.M.; Lo, W.C.J.; Bishop, S.M.; Alberty, J.B.; Cowell, S.M.; Mclaughlin, M.L. De novo antimicrobial peptides with low mammalian cell toxicity. J. Med. Chem. 1996, 39, 3107-3113. [CrossRef]

38. CLSI. Performance Standards for Antimicrobial Susceptibility Testing: Twentythird Informational Supplement; Clinical and Laboratory Standards Institute: Wayne, PA, USA, 2013.

39. Coutinho, H.D.M.; Costa, J.G.; Lima, E.O.; Falcão-Silva, V.S.; Siqueira-Júnior, J.P. Enhancement of the antibiotic activity against a multiresistant Escherichia coli by Mentha arvensis L. and chlorpromazine. Chemotherapy 2008, 54, 328-330. [CrossRef]

40. Cunha, F.A.B.; Wallau, G.L.; Pinho, A.I.; Nunes, M.E.M.; Leite, N.F.; Tintino, R.S.; Franco, J.L. Eugenia uniflora leaves essential oil induces toxicity in Drosophila melanogaster: Involvement of oxidative stress mechanisms. Toxicol. Res. 2015, 4, 526-534. [CrossRef]

41. Coulom, H.; Birman, S. Chronic exposure to rotenone models sporadic Parkinson's disease in Drosophila melanogaster. J. Neurosci. 2004, 24, 10993-10998. [CrossRef]

Sample Availability: Samples of the all compounds assayed are available from the authors.

(C) 2020 by the authors. Licensee MDPI, Basel, Switzerland. This article is an open access article distributed under the terms and conditions of the Creative Commons Attribution (CC BY) license (http://creativecommons.org/licenses/by/4.0/). 